\title{
Science, Engineering, and Technology Innovation for Global Human Chal- lenges
}

Prof. Melany M. Ciampi, Safety, Health, and Environment Research Organization

Dr. Melany M. Ciampi is Professor of Electrical and Computer Engineering. Currently is the President of World Council on System Engineering and Information Technology (WCSEIT), President of Safety Health and Environment Research Organization (SHERO), President of World Council on Communication and Arts (WCCA), Vice-President of Science and Education Research Council (COPEC), Vice-President of Fishing Museum Friends Society (AAMP) and Secretary of Education Society of the IEEE (IEEE-EdSoc). She is also Chair of Intersociety Cooperation Committee of Education Society of the IEEE (IEEE-EdSoc) since 2011, Co-Chair of Working Group "Ingenieurpädagogik im Internationalen Kontext" in IGIP (Internationale Gesellschaft für Ingenieurpädagogik) since 2002, Member of Strategic Planning Committee of Education Society of the Institute of Electrical and Electronics Engineers, Inc (IEEE-EdSoc) since 2009 and Board Member of "Global Council on Manufacturing and Management" (GCMM) since 2004.

\section{Prof. Claudio da Rocha Brito, Science and Education Research Council}

Dr. Claudio da Rocha Brito is Professor of Electrical and Computer Engineering. Currently is the President of Science and Education Research Council (COPEC), President Elect of IEEE Education Society (2015-2016), President of Fishing Museum Friends Society (AAMP), President of (Brazilian) National Monitoring Committee of "Internationale Gesellschaft für Ingenieurpädagogik" (IGIP), Vice President of International Council for Engineering and Technology Education (INTERTECH), Vice President of World Council on System Engineering and Information Technology (WCSEIT), Vice President of Safety Health and Environment Research Organization (SHERO) and Vice President of World Council on Communication and Arts (WCCA). He is Chairman of Working Group "Ingenieurpädagogik im Internationalen Kontext" since 2002, Member of International Monitoring Committee in IGIP since 2004, Member of Strategic Planning Committee of Education Society of the Institute of Electrical and Electronics Engineers, Inc (IEEE-EdSoc) since 2009, Board Member of "Global Council on Manufacturing and Management" (GCMM) since 2004 and Director of Brazilian Network of Engineering (RBE) since 1998. He is also Member of Board of Governors of International Council for Engineering and Technology Education (INTERTECH) since 2000 and Member of Board of Governors of Education Society of the Institute of Electrical and Electronics Engineers, Inc (IEEE-EdSoc) since 2001.

\section{Prof. Rosa Maria Castro Fernandes Vasconcelos, Universidade de Minho}

Rosa Maria de Castro Fernandes Vasconcelos is a Associate Professor at the Department of Textile Engineering since 2005. Degree in Textile Engineering by the University of Minho. Professor at the University of Minho since 1984. PhD in Engineering -Technology and Textile Chemistry by the University of Minho in 1993. Rieter Award, 1993.

Responsible for several curricular units in the integrated study cycles in Textitle Engineering and Engineering and Industrial Management, in the 1st cycle course of Design and Fashion Marketing, and also in the 2nd cycle courses of Fashion Design and Communication, Textile Chemistry, Advanced Textiles and Design and Marketing.

Head research and research member of several R\&D projects, has presented as main author or co-author many dozens of scientific journal papers and communications in international conferences.

President of the Pedagogical Council of the School of Engineering since 2011 and Vice-Dean of School of Engineering

\section{Prof. Luis Alfredo Martins Amaral, University of Minho - ALGORITMI}

Born in 1960 is Associate Professor at Department of Information Systems in the School of Engineering of University of Minho. 
Researches and teaches in the areas of Information Systems Planning, Information Systems Management and the Information Society, especially in the field of Public Administration.

Chairman of the Board of the GCC - Computer Graphics Center since 2005. Pró-Rector of University of Minho between 2006 and 2009. President of the National College of Informatics (Order of Engineers) since 2010.

\section{Prof. Victor F. A. Barros Ing.-Paed IGIP, Science and Education Research Council}

Prof. Victor Freitas de Azeredo Barros, Ing.-Paed IGIP is Executive Secretary of Science and Education Research Council. He is Researcher at AlgoritmiCentre/University of Minho; University of São Paulo; Mackenzie University; Pontifical Catholic University of Goias; Goiás Federal Institute; Amapá Federal Institute and Catarinense Federal Institute. He is Editor-in-Chief of the Brazilian Journal "Cadernos de Educação, Tecnologia e Sociedade". He is Editorial Chair of the Safety, Health and Environment World Congress; International Conference on Engineering and Computer Education; World Congress on Communication and Arts; World Congress on Systems Engineering and Information Technology and Editorial Chair of the International Conference on Engineering and Technology Education. He is Member of the Research Team in Information Systems and Technologies for Transformation of Organizations and Society; Applied Computing; Interaction and Food Plants, Science Teaching; Education, Management and Environment and member of the research team of Center for Studies and Research and Engineering Education. He has more than 110 papers published in several congresses and he has organized more than 30 congresses around the world. 


\title{
Science, Engineering and Technology Innovation for Global Human Challenges
}

\begin{abstract}
This paper describes the engineering program designed by COPEC - Science and Education Research Council's education research team, in which the so called 'Working with Communities' course is included. It provides 3rd year engineering students the chance to work as consultants to foster an entrepreneurial community in the city. The idea is to create an Innovative Office, to which local entrepreneurs can resort to in order to discuss and find sustainable solutions for a specific problem or a project. So far, the project has worked relatively well. Student groups are working hard and the results have been positive.
\end{abstract}

Keywords: community, enterprise/university, internship, volunteer, project based learning.

\section{Introduction}

Science, Engineering and Technology cross nearly every facet of modern life and, as problem solvers, engineers are perfectly capable of managing entrepreneurial activities, mastering innovative ways of business development, when they spend time and efforts understanding and acting in the field. Engineers rely on science and methods for analysis to ensure the quality and liability of design; nevertheless a pinch of creativity is required in order to find innovative solutions for economic and entrepreneurial problems. So, at present, engineers with technical skills must also learn how to work in interdisciplinary teams, how to develop designs rapidly, how to manufacture sustainably, how to combine art and engineering and how to address global markets. Providing opportunities in the work market for future engineers has become now part of university training, as a way to assure also the future competitiveness of universities. .

In many places, enterprises and universities have still difficulties in working together, it is up to engineering schools and universities to have the initiative to enhance their programs, to assure the proper training for future professionals that can perform in this mutant work environment of the 21st Century. According to the report "The Engineer of 2020", developed by the National Academy of Engineering, USA, which paints a picture of a dynamically changing and evolving world: "The successful future engineer will need strong analytical skills, practical ingenuity, creativity, good communication skills, business and management knowledge, leadership, high ethical standards, professionalism, dynamism, agility, resilience, flexibility, and the pursuit of lifelong learning".

Currently, the opportunities for professionals seem to be very narrow, once economic crisis is impacting countries and communities worldwide, as the result of a natural cyclic wave of economy, until a new economic model starts to work somehow. To provide future professionals an opportunity in the work market has now become part of university training as a way to assure the future of university. 
COPEC - Science and Education Research Council's education research team has designed and implemented a program for engineering students which is called "Working with Communities Course", providing 3rd year engineering students the chance to work as consultants for the entrepreneurial community in the city. The goal is to offer a space that has been named "Innovative Office", to which local entrepreneurs can resort to in order to discuss and to find sustainable solutions for a specific problem or project

It is good for students, since they work using their creativity to design and present solutions within the constraints of ethical practice grounded in science and engineering methods and standards. The process involves face-to-face meetings and discussions with entrepreneurs of the city, from the presentation of the problem until the delivery of the plans. Once engineers are part of society it is important that they have a stronger interaction with the wider public. So the goal of including this course in the program is to provide students the opportunity to work closely with the real local entrepreneurship environment. Apart from this, engineers need to develop broad fundamental understanding of their professional responsibilities, as well as the need to be entrepreneurial in order to understand and contribute in the context of market and business pressures. If engineers can work with the public to explain how engineering can help address their problems, and to help them to decide which are the most effective and affordable ways to address their concerns, the community can make great progress and improvements. It will surely be a great acquisition for the city business community as well as for the students themselves, once they can get a glimpse of what it is to engineer in real world.

This project is being developed in partnership with a City Hall as a way to improve entrepreneurship in the region, aiming at fostering employment and private initiatives to change community's profile.

\section{COPEC: Science and Education Research Council}

COPEC - Science and Education Research Council is a multi-disciplinary organization that is a leader to advance science and its application to the development of technology serving society. It started its activities sixteen years ago and since then this organization has made a major contribution to the development of science and education, working to increase the best practices in several research fields.

Integration activities promoted by COPEC provide a qualified coordination and building partnerships because COPEC is an organization that brings together scientists who share the mission of promoting and developing science, technology and education.

The objectives of COPEC are to promote professionalism, integrity, competency, and education; foster research, improve practice, and encourage collaboration in the different fields of sciences.

Contents, tools and services provided by COPEC, through courses, publications and consultations with national and international experts, contribute to the promotion of the professional who wants to be privy of the new achievements and the service of man to technology. 
COPEC enjoys respect and recognition internationally characterized by the open discussion, the free exchange of ideas, respectful debate, and a commitment to rigorous inquiry. Its IIE International Institute of Education - is a bold and resilient source of innovation in higher education [1].

\section{Educational Aspects in Current Reality}

Work environment worldwide has changed drastically, and today millions of professionals are also unemployed, even in advanced economies. On the other hand, businesses in economically advanced countries claim that they are often not able to find workers with the required skills. It is a fact that this is a symptomatic dysfunction due to the structural changes that are transforming the nature of work and reshaping employment opportunities. This shows that organizations and policies are not keeping up with the changes in business practices and new technologies which are defining what kind of jobs will be created and where they will be located. So there is a need for companies to redefine how and where different tasks have to be carried out, requiring new skills and new employer and employee relationships [2].

It is also important to attempt that globalization has been expanding access to low-cost talent professionals and creating a greater need for workers with higher levels of education and specific skills in order to perform in advanced economies. Under skilled workers are disappearing due to automation and low-cost labour market abroad. In this world scenario, education and training should be seen as vital economic priorities by governments. However, it is still possible to observe the neglect of some nations, perhaps due to lack of political interest other than electoral. Although governments need to invest in the entire system that builds workforce skills, in some places it is up to private initiatives to offer opportunities for young ambitious talented professionals, who can cooperate for a better future of generations to come. There is no better place than universities to offer these opportunities, pushed by the enterprises. It is important for nations to train highly skilled native-born citizens as well as to attract highly skilled immigrants in order to be competitive in a global scale and assure a future for the people [3].

Finally, government agents should be aware of the fact that if there is no production system, there will be no financial resources to maintain the social assistance system. This idea of an innovative office will help to generate more quality services to improve industry service, as well as the production system generating opportunities and jobs, which is a need everywhere in the world today [4].

\section{Details of the Innovative Office}

Students who are interested in the project register for economics classes. After three weeks of classes they take part in a training class in order to learn how to cause a first good impression with their future clients. This is followed by a period at 'The Innovative Office', in the City Hall. Their work starts when they register for the project, which is an opportunity of intensive internship, early in the program.

The first idea was to offer an extra course and invite students to enroll the course. However, as it had, in a first moment, a low number of interested students, the coordination of the project 
decided to offer also an internship opportunity. This idea reached the desired goal and a larger number of students enrolled the course/internship opportunity.

There are some "soft" skills that are required, since the students will be facing a real working environment: a positive attitude because it is a valuable interpersonal skill; writing well is another one, as well as leadership and responsibility; being able to take action and networking with colleagues and enterprises, besides computer skills, planning and organizing.

An interesting challenge provided by the project development is that students have to be committed with sustainable and feasible simple solutions for medium and small business problems and as low cost as possible. These are the headlines and main ideas of the entire training they have prior the practical period.

Below, there is the picture of a meeting of a team of students that happens almost every day:

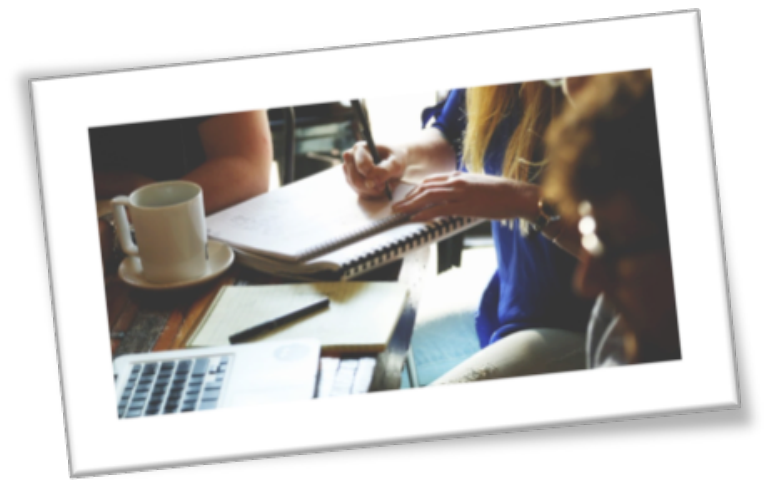

Fig 1 MeETING

Once at 'The Innovative Office', for a period of at least four months, students have to establish goals and work towards achieving them. Students are challenged to start a professional relationship with a possible client, leading them to be open and honest. They will start identifying a problem and then find a theoretical background and a methodical approach to solve the problem within a realistic time frame, towards the completion of the project, and at reasonable expenses. This is followed by the implementation period and the refinement of procedures in order to solve the problem and deliver the project.

Students are volunteers; however, they get a small payment in order to cover the expenses with transportation and meals. It's also important to point out that students are not doing lots of work, since volunteer/internships are unpaid labour. The whole point of the volunteer/internship is to gain experience, make contacts and gain references.

Work experience seems the obvious answer and that is where internships can come in handy. General work experience can be any kind of employment where future engineers can gain valuable transferable 'soft' skills such as communication and organization, among others. So internships tend to be more structured and in the field that eventually students want to move into. 
After the accomplishment of the project, students send a report to the Head Director of The Innovative Office to be included in both, the program's and the students' portfolio [5].

\section{Adopted Methodology for the Development of the Project}

The whole process has been developed in steps and it required a person in charge of the project, which in this case is the professor specially hired as the Head Director of "The Innovative Office" since the very beginning. The Head Director will keep the project working and collect all data for enhancement of the process throughout its development.

The project starts with a course named "Introductory Economics Topics" which may include an overview of: economic theory, econometrics, macroeconomics, microeconomics, economics research methods, economic policy, game theory and mathematical methods for economic analysis. Its main goal is to give students the opportunity to have a glimpse of the necessary economic aspects to understand and boost the economic commonwealth of the region. The hired teacher is a professional who is also prominent in his field in order to attract students and enhance the quality of the program. The model chosen is the one-week intensive class about the topics, in order to provide students the basic knowledge and the means to research further information when necessary. This step will take nine weeks before the students can start their journey in the project.

The legal aspects are up to the consultancy of law office of the City Hall in order to assure that some other issues related with legal actions and measures are avoided.

The research team proposes to offer this course for all engineering programs of the Engineering School of the university involved in the project, to have a critical mass of specialties to perform in the consultancy field for the community. However, students are invited to join the project, which in fact reduces the number of interested students. The key is to have really interested students involved in a first stage, so that it can be expanded to all school programs as a way to increase the quality of the program [6].

Below is the picture of the office where the project is developed:

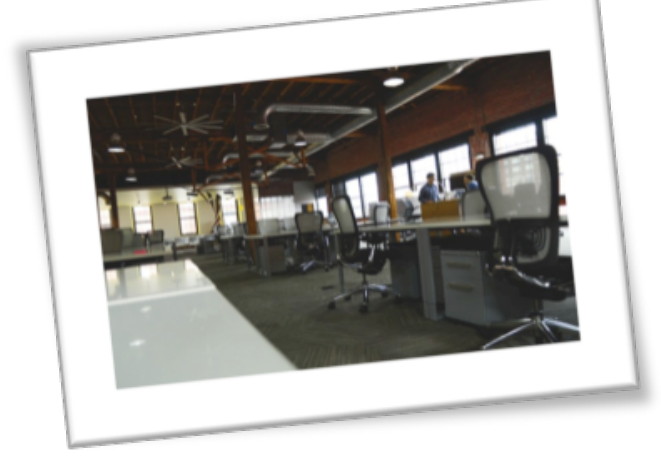

FIG 2 WORKSPACE

Once the number of interested students from all the programs of the referred engineering school is established, the next step is to hold a meeting with students and define a schedule for the activities to be held at the office, located in the City Hall building which is offering this service to the 
community. The workspace is basically a clean neat room with tables, chairs, computers and a telephone line.

It is up to the City Hall to advertise the service "The Innovative Office" to the local community. The university is responsible for providing the students and the necessary laboratories. In case a laboratory is used, a fee is charged to the consultant to cover basic material and energy. There is another professor in charge of mentoring the students' team for a determined period as volunteer work, in order to help refining their proposed projects to their clients.

The next step is to have students working in teams at the offices, available to receive possible clients. The students welcome the client; start a professional relationship and work in order to solve the presented problem.

Their work starts with a visit to the enterprise where the business takes place, collecting all data, followed by the search for ways to best solve the client's issue. This means that they have to work hard in teams to find out "The Best Solution" for the presented problem in a "Certain Period of Time", which the team can establish and must honour. It is a simple concept that works because of the commitment of all people involved in the process.

Both, the university and the City Hall, are committed to provide this service for a determined period of time in a first moment and to enlarge it if there are conditions to do it. An agreement is signed between both organizations for a certain period, which can be ended by mutual decision. The implementation of the project started in 2013 and the office started working effectively in August 2014, mainly due to City Hall bureaucracy.

\section{Schedule for $2015 / 2016$}

The maximum number of groups per period is 5, with an average of 4/5 students each. Each group can work with a maximum of 2 clients in order to have a good performance since it is conditioned to students 'availability, regarding classes and studies at the university. . The project must be delivered at least before the end of their period at the office.

Below is the organized schedule for 2015/2016:

\begin{tabular}{|l|l|l|}
\hline 1st period & March/April/May/June & 4 groups with 4 people \\
\hline 2nd period & July/August/September/October & 5 groups with 3 people \\
\hline 3rd period & November/December/January/February & 3 groups with 4 people \\
& & \\
\hline
\end{tabular}

FIG 3 SCHEDULE 
It is important to have the office working all year round, so that students can choose a suitable period. In any case, the schedule is organized by the Head Director of The Innovative Office together with the students.

\section{Main Objectives of the Project}

The project objectives are essentially the development of engineers with skills to perform in the future work market especially in economics, as high skilled professionals are a demand in every country, which widens their job opportunities. The following skills are important since they are already required:

- Broad knowledge of different fields in economics;

- Enhanced research skills for researching for clients;

- Entrepreneurial skills;

- Knowledge of theoretical and empirical approaches to economics;

- Management skills;

- Solid understanding of economic practices, principles and theory;

- Strong command of economic models, tools and techniques including particular statistical techniques;

- Strong numerical and analytical skills;

- Strong oral and written communication skills, including preparation and delivery of professional, technical and non-technical reports and presentations;

- Time management skills.

At the end of the period the students will be able to understand the real economic and social impact of engineering in this century. Another target goal to be achieved is to foster among them the entrepreneurial mind to pursue other opportunities than finding a job in a company [6]. For the university the final goal is to attract more students and enlarge the number of students in engineering programs. Besides this, by law, universities should provide services to the community, what serves for both student's practical period and society access to consultancy in engineering that is very expensive otherwise. For the City Hall, this is another community service funded by federal government, which could be turned into votes for future elections.

\section{Project status}

The groups and the director of the project are doing the assessment of the project in order to identify the weak and strong points in order to make adjustments for future activities.

Currently the project has worked relatively well. Student groups are working hard and the results have been positive. Customers of the office present a high level of satisfaction. This information is based on the result of a survey that was completed at the end of the project together with the participant companies.

The students claim that the project is a very good opportunity to know their own limits and capabilities. The difficulties they face are related to the fact that they have to combine the project work with studying hard to accomplish the engineering program. 
They have provided good feedback and are working hard to finish the engineering program, certain that engineering is what they want to do in life.

The City Hall evaluates it as a good service offered to the community and intends to keep "The Innovative Office" open for another year. The constrains are related to the political environment, meaning that the project will last as long as there is political interest by the current government bodies at least until 2016 [7].

Statistics and numbers details will be available in a couple of months when it is expected a coordination meeting, between the engineering team and city hall coordinators, around august 2016, to establish the future of the project.

It is important to point out once more that the students perform as professionals, what provides them a very valuable experience under the perspective of professional performance. It is a project that benefits not only the students and the university, which can provide a period of internship but also the city's community of commerce and industry.

The research aspect of this project relies on the large experience in developing educational projects and a transdisciplinary team with solid careers.

\section{Conclusions}

Maybe the best outcomes of the project are the skills that the students develop during the process in the "Innovative Office", the perception that they have to take risks and turn today's failures into the seeds of tomorrow's success. A first result seen during this process is that the project helps the students to experience what it is to be an engineer early during their studies.

Another relevant conclusion is that they can evaluate their own performance and make adjustments. Furthermore, they develop skills such as human interaction, work in team, and work under deadlines and how to find real sustainable and feasible solutions.

The pedagogical aspects of the program are the key factor for its success, which are the extra courses of economics taught by specialists and the research practice that students have to develop in order to get the basis for project development. It is a very rich experience for students and shows them that they need to be very self-disciplined and to avoid procrastination.

It has been working well because of the quality performed by students, who at the end of the internship already have proposals for jobs.

\section{Acknowledgment}

This work has been financed by FEDER funds through the Competitivity Factors Operational Programme COMPETE: POCI-01-0145-FEDER-007136 and POCI-01-0145-FEDER-007043 and FCT - Fundação para a Ciência e Tecnologia within the Project Scope: UID/CEC/00319/2013. 


\section{References}

[1] www.copec.eu

[2] http://www.teachthought.com/learning/10-characteristics-of-a-highly-effective-le arning-environment/

[3] http://www.pewinternet.org/2014/04/17/us-views-of-technology-and-the-future/

[4] Brito, C. da R.; Ciampi, M. M.; Vasconcelos, R. M. C. F.; Amaral, L. A. M.; Barros, V. F. A. Engineering Impacting Social, Economical and Working Environment. In: American Society for Engineering Education Annual Conference, 120, Atlanta, 2013. 2013 ASEE Annual Conference Proceedings. Atlanta: ASEE, 2013.

[5] Brito, C. da R.; Ciampi, M. M.; Vasconcelos, R. M. C. F.; Amaral, L. A. M.; Barros, V. F. A. Innovative on Demand International Engineering Programs. In: European Society of Engineering Education Annual Conference, 42, Birmingham, 2014. Educating Engineers for Global Competitiveness. Birmingham: SEFI, 2014.

[6] Ciampi, M. M.; Brito, C. da R.; Amaral, L. A. M.; Vasconcelos, R. M. C. F.; Barros, V. F. A. A Program Designed to Empower Engineering Educators. In: ASEE/IEEE Frontiers in Education Annual Conference, 44, Madrid, 2014. Opening Innovations and Internalization in Engineering Education. Madrid: FIE, 2014. p. 1925-9.

[7] Barros, V. F. A.; Ciampi, M. M.; Brito, C. da R.; Vasconcelos, R. M. C. F.; Amaral, L. A. M. Engineering Programs for Engineers - A global Higher Education Perspective. In: International Society of Engineering Education (IGIP) Annual Symposium, 43, Dubai, 2014. Engineering Education for a Global Community. Dubai: IGIP, 2014. p. 1039-42. 